\title{
Antecedentes de la Cultura Tributaria en México
}

\author{
Background of the Tax Culture in Mexico
}

\author{
ANDRADE-OSEGUERA, Miguel Ángel†๋*, PAREDES-BARRÓN, Adriana, BÁRCENAS-PUENTE, \\ José Luis y SILVA-CONTRERAS, Juan
}

Universidad Tecnológica del Suroeste de Guanajuato. Carretera Valle de Santiago - Huamimaro Km. 1.2, 20 de Noviembre, 38400 Valle de Santiago, Gto.

ID $1^{\text {er }}$ Autor: Miguel Ángel, Andrade-Oseguera / ORC ID: 0000-0002-7926-9162, Researcher ID Thomson: S-65862018, CVU CONACYT ID: 509374

ID $1^{\text {er }}$ Coautor: Adriana, Paredes-Barrón / Researcher ID Thomson: S-6586-2018, arXiv Author ID: 73Y8LW-FGQ28, CVU CONACYT ID: 947184

ID $2^{\text {do }}$ Coautor: José Luis, Bárcenas-Puente / ORC ID: 0000-0002-1051-8861, Researcher ID Thomson: S-8603-2018, CVU CONACYT ID: 743962

ID $3^{\text {er }}$ Coautor: Juan, Silva-Contreras / ORC ID: 000-000-1913-9910, arXiv Author ID: LAJ9UT-QHDDL4, CVU CONACYT ID: 509502

DOI: $10.35429 / J L A .2019 .8 .3 .21 .31$

Recibido 01 de Mayo, 2019; Aceptado 30 de Junio, 2019

\section{Resumen}

El pagar impuestos, suele ser un trámite engorroso para los ciudadanos y, en ocasiones se resisten a cumplir con la obligación de contribuir para el gasto público, el no saber claramente a donde van a parar esos pagos y la falta de una cultura fiscal los contribuyentes incurren en faltas administrativas. A razón de fortalecer la Cultura Tributaria en el país, se requiere que la población tenga el conocimiento sobre el tema, y una manera para adquirir dicho conocimiento, es entendiendo a través de la historia, la importancia del tema y de la responsabilidad tributaria. En el presente trabajo, se realiza un análisis de información sobre la historia de la cultura tributaría en México, que de la pauta de conocer la situación económica, financiera, social y política de nuestro país, generar el conocimiento sobre el civismo fiscal, y que sirva de base para comprender porque es importante que los ciudadanos contribuyan con el Estado, Federación y Municipio. De igual manera a través de la investigación contribuir con la generación del conocimiento sobre la importancia del pago de impuestos y el fortalecimiento de valores, que permitan generar una cultura que cuando se tenga que contribuir sea sabiendo que es para beneficio de la misma sociedad y su economía.

Cultura tributaria, Impuestos, Contribuciones

\begin{abstract}
Paying taxes is usually a cumbersome process for citizens and, sometimes they resist complying with the obligation to contribute to public spending, not knowing clearly where these payments are going to end and the lack of a tax culture for taxpayers incur administrative failures. In order to strengthen the Tax Culture in the country, it is required that the population have the knowledge on the subject, and a way to acquire said knowledge, is through history, understanding the importance of the subject and tax responsibility. In the present work, an analysis of information on the history of tax culture in Mexico is carried out, which of the guideline of knowing the economic, financial, social and political situation of our country, generating knowledge about fiscal citizenship, and that serve as a basis for understanding why it is important that citizens contribute to the State, Federation and Municipality. In the same way, through research, contribute to the generation of knowledge about the importance of paying taxes and strengthening values, which allow generating a culture that, when it is necessary to contribute, is knowing that it is for the benefit of society itself and its economy.
\end{abstract}

Tax culture, Taxes, Contributions

Citación: ANDRADE-OSEGUERA, Miguel Ángel, PAREDES-BARRÓN, Adriana, BÁRCENAS-PUENTE, José Luis y SILVA-CONTRERAS, Juan. Antecedentes de la Cultura Tributaria en México. Revista de Aplicaciones del Derecho. 2019. 3-8: 21-31.

\footnotetext{
*Correspondencia al Autor (Correo Electrónico: maandrade@utsoe.edu.mx)

$\dagger$ Investigador contribuyendo como primer autor.
} 


\section{Introducción}

En el trabajo se muestra una reseña histórica, conocer la implementación de los impuestos en otras épocas y poder comprender porque son necesarios los impuestos y la necesidad de cubrirlos en la actualidad. De igual manera entender la actividad financiera y el derecho financiero, esto para identificar la relación entre las contribuciones, impuestos y sus derivados. La legislación es un punto importante, ya que determina la implementación de los impuestos y sus clasificaciones, el uso que se les da y a quien están dirigidos para su cumplimiento.

$\begin{array}{ccccc}\text { La } & \text { Cultura } & \text { Tributaria que } & \text { los } \\ \text { ciudadanos } & \text { tienen } & \text { con el pago } & \text { de }\end{array}$
contribuciones y la necesidad de crear un servicio de atención al contribuyente, adecuado para que el, es parte del análisis.

Parte del problema es el desconocimiento por parte de la población de la importancia de los impuestos para la sociedad y las consecuencias de su evasión, la necesidad de crear un civismo fiscal, desde la educación primaria para que las próximas generaciones crezcan con una Cultura Tributaria que aporte a un crecimiento en las contribuciones, captar recursos que de igual manera sean empleados para el beneficio de la misma sociedad.

El pago de los impuestos puede llevarse a cabo mediante la aplicación de la fuerza pública ó apelando a la razón de los contribuyentes. Las fuerza se manifiesta en las leyes establecidas por el Estado y que son de cumplimiento obligatorio, mientras que la razón solo puede estar dada por una Cultura Tributaria basada en una fundamentación sólida. Para muchos ciudadanos el tributar está relacionado con su percepción, que puede ser positiva o negativa sobre el uso que se le da a los recursos obtenidos, por funcionarios que de igual forma carecen de una ética necesaria de implementar en su formación académica.

Por otra parte la falta del conocimiento sobre la Constitución Política y las Leyes establecidas, hace que los ciudadanos no comprendan la magnitud que tiene el acto de no contribuir para con el gasto público de la nación mediante el pago de sus impuestos, a través de estrategias para disminuir los montos correspondientes o caso nulo a estos.
Crear una cultura fiscal (Civismo Fiscal) no es fácil sabiendo que existen varios elementos que sean negativos o por una falta de conocimiento. El Civismo Fiscal es la actitud responsable, por parte del ciudadano, en el cumplimiento de las obligaciones tributarias de manera oportuna y voluntaria. La Cultura Tributaria es el conjunto de valores que se manifiestan en el cumplimiento permanente de los deberes tributarios con base en la razón, la confianza y la afirmación de los valores de ética personal, respecto a la ley, responsabilidad ciudadana y solidaridad social de los contribuyentes. (SAT, 2018).

El cumplir con obligaciones en tiempo y forma y de contribuir para el gasto público de la Federación, Estado, Municipio, se vuelve difícil, debido a tantos problemas que surgen para determinar las contribuciones y el manejo de las mismas. El objetivo es analizar la información histórica sobre la educación tributaria existente, para generar el conocimiento sobre el arraigo del civismo fiscal, y poder entender la importancia de la tributación, proporcionar información sobre aspectos basados en la política fiscal, con idea de acrecentar una actitud de cumplimiento de las responsabilidades tributarias, aplicando la razón de los contribuyentes ante las obligaciones que se tienen, con el propósito de que contribuyan con lo que les corresponde.

\section{Metodología a desarrollar}

Se analiza la historia de la tributación en México para identificar el antecedente que señala, todo contribuyente que realice actividades empresariales, así como los que obtengan ingresos por otro tipo de conceptos en el país, debe de contribuir para con el gasto público, a través del pago de los impuestos establecidos en la normatividad vigente. Se analiza la normatividad que da origen a una política fiscal.

\section{Antecedentes históricos de las contribuciones en México}

El saber cómo surgieron las contribuciones en nuestro país es conocer otro ámbito importante de México y su historia, para comprender la importancia de las actividades económicas en el desarrollo del país. 


\section{México prehispánico}

Para comenzar se conoce que en el México Prehispánico los tributos que se pagaban eran de dos tipos: los que pagaban los pueblos que eran sometidos mediante guerras y los que debían pagar los habitantes mexicas. En ese entonces al establecerse México Tenochtitlán, surge la etapa de expansión y dominio de los aztecas. Los pueblos a quien sometían, les imponían cargas tributarias, tales como entregar prendas de algodón, plumas de aves, telas de varias fibras, cigarros, bolas de caucho para el juego de pelota y también metales, preciosos, animales e incluso mancebos a los que se les arrancaba el corazón para ofrecerlo a sus dioses. Los tributos que se cobraban a los pueblos que sometían, no se utilizaban para beneficio de las comunidades que lo aportaban; si no, para cubrir las necesidades de los gobernantes y del pueblo dominante.

Los aztecas tenían un sistema jerárquico social, reglamentado con el uso de colores y decorados de las prendas de su indumentaria.

El ser mexica obligaba al soberano redistribuir los bienes en beneficio de los habitantes del imperio, lo que propiciaba una importante obra pública que facilitaba el tránsito, el comercio y las artes.

El verbo tributar cobró tal importancia que los aztecas se organizaron para facilitar la recaudación: nombraron entonces a los "Calpixquis", primeros recaudadores, su función la implementaban llevando una vara en mano y un abanico en la otra.

La recaudación de esos pueblos requería de funcionarios que llevaran un registro pormenorizado de los pueblos y ciudades quienes tributaban, así como el conteo y valuación de las riquezas recibidas.

La matrícula de Tributos es uno de los documentos más importantes de los códices dedicados a la administración y a la Hacienda Pública. Los "Tequiámatl" (papeles o registros de tributos) fue un género de esos códices, relacionados con la administración pública dentro del Imperio Mexica. (SÁNCHEZ LEÓN, 1999)
Existían varios tributos que se daban según la ocasión; de guerra y religiosos, entre otros. Los tributos a que estaban obligados los pueblos sometidos a los aztecas eran en especie o mercancías que variaban según la provincia, población, riqueza o industria; o en servicios especiales que los habitantes de los pueblos sometidos estaban obligados a prestar.

\section{La colonia, periodo virreinal}

A la llegada de Hernán Cortés a México, se sorprendió con la organización que el pueblo azteca tenía. La conquista de territorios se volvió una deuda con los soldados que participaron en tal campaña militar, así que repartió el oro que encontró y ofreció tierras e indios para que trabajasen en su provecho. Cortés cambió el pago de los tributos del pueblo azteca de flores y animales, por alimentos, piedras y joyas. Por lo que atañe al pueblo Aztecas, Porras y López nos dice: "En época precortesiana, es bien sabido que el poderoso Imperio Azteca imponía fuertes tributos a los pueblos vencidos. En los Códices pre y postcortesianos constan interminables listas de objetos de algodón, telas de varias especies de fibras, productos naturales y aun metales preciosos que los pueblos vencidos debían enviar como tributos a la Gran Tenochtitlán. (PORRAS Y LÓPEZ, 1967). Después de la caída de México, surgió la Real Hacienda que se dedicó al cobro de impuestos, estaba constituida por un tesorero, un contador que llevaba el registro de las contribuciones en libros, un factor que cobraba los impuestos, alguien que inspeccionaba, y oficialmente la Real Hacienda que era una especie de judiciales fiscales, dio origen a la monarquía española denominada Quinto Real.

La función del tesorero era guardar en su caja real todas las barras de oro o plata e inclusive monedas que recibía. Esta caja se abría con tres llaves, que por seguridad se encontraban en manos de tres personas distintas: el contador, el tesorero y el gobernador. El diezmo y la primicia eran otros impuestos implementados por el clero a las provincias. Gracias a ellos la iglesia acumuló grandes riquezas, con las que atendió obras de construcción, beneficencia, educación y arte. Para realizar todos estos trabajos se contaba con haciendas, conventos, casas, templos, escuelas, hospitales, asilos y orfanatos. 
Establecida la Colonia, los indígenas pagaban sus impuestos también con trabajo en minas, haciendas y granjas. En 1573 se implanta la alcabala (pago por pasar mercancías de un Estado a otro) y después el peaje (derecho de paso). El ramo que más se atendió creándose todo un sistema jurídico fiscal con el objeto de obtener el máximo aprovechamiento de su riqueza para el Estado, fue el de las minas y sus productos ya que eran la principal fuente de riqueza.

\section{México Independiente}

La ideología de libertad proveniente de Europa, influyo en la Nueva España sirvió para preparar una revolución que terminaría con el régimen colonial.

En 1810, Hidalgo, Morelos y los caudillos de la Independencia, lucharon contra la esclavitud y por la abolición de alcabalas (impuesto indirecto $10 \%$ del valor de lo que vendía o permutaba), gabelas (gravámenes) y peaje (pago de derecho de usos de puentes y caminos). En ese año la Orden Real de la Nueva España dictó que los indios quedaban eximidos del pago de contribuciones. Entre las proclamas de los insurgentes se observan las siguientes:

- Que todos los dueños de esclavos deberán darles liberad dentro del término de diez días, bajo pena de muerte si no se cumpliera.

- Que cese la contribución de tributos respecto a las castas que lo pagan y toda exacción que a los indios se les exija.

- Que en todos los negocios judiciales, documentos, escrituras y actuaciones, se haga uso de papel común para dejar de pagar impuestos por el papel sellado.

En marzo de 1812 se expidió la Constitución de Cádiz, donde se dispuso que las Cortes establecerían anualmente las contribuciones, directas o indirectas, generales, provinciales o municipales y que dichas contribuciones se pagarían en proporción a los haberes para los gastos del Estado. También dispuso que las contribuciones fueran proporcionadas a los gastos de los servicios públicos. (ESCOBAR RAMÍREZ, 1999)
El Sistema Fiscal se complementa expidiendo el arancel para el Gobierno de las Aduanas Marítimas, siendo éstas las primeras tarifas de importación publicadas en la República Mexicana. Así mismo, se modifica el pago de derechos sobre vino y aguardiente y se sanciona la libertad para extracción de capitales extranjeros. En 1821 se suprimen por decreto los siguientes impuestos:

- $1 \%$ de diezmo y real señoreaje.

- El derecho o tributo de 8 maravedíes (moneda española) por marco de plata, pago que se hacía por el proceso de afinación de las pastas de oro y plata.

- Se suprimen todos los derechos que gravaban las pastas (proceso de aleación) de oro y plata, así como a la moneda, y que les habían sido asignados durante la guerra de Independencia.

En 1822 para tratar de arreglar la situación económica se aplicaron nuevas disposiciones Hacendarias, Se modificaron los derechos sobre el vino y el aguardiente, aumentándose la tasa para los extranjeros. El congreso otorgó la primera exención de impuestos en un caso particular; se permitió la introducción de cinco imprentas sin impuestos y derechos. En 1824 con la presidencia del General Guadalupe Victoria, se creó la Contaduría Mayor de Hacienda, integrada por Hacienda y por Crédito Público. La sección de crédito Público debía comprobar el estado de la deuda nacional, las sumas autorizadas y los intereses cubiertos. A la par, se fundan los principios jurídicos sobre los que se basó la Hacienda Pública. Éstos quedaron establecidos en el acta Constitutiva. Asimismo, se sancionó el principio de que no podrá hacerse ningún pago o erogación que no esté comprendida en los presupuestos, excepto en el caso de que sea aprobado por el Congreso.

\section{Reforma}

Entre los años de 1858 y 1861 se dio la guerra de Reforma. En estos años se enfrentaron conservadores y liberales, llevando al pueblo nuevamente a un periodo de inestabilidad. Benito Juárez y otros liberales expidieron las Leyes de Reforma, entre las que destaca la Ley de Desamortización de los Bienes del Clero. Surgieron otras leyes: 
- Separación de la Iglesia y el Estado.

- Eliminación de órdenes religiosas.

- Matrimonio y registros civiles.

- Secularización de cementerios.

- Libertad de cultos.

Benito Juárez se vio obligado por la guerra, a instalar su gobierno en diferentes ciudades del país, hasta que el triunfo de los liberales regresó a la capital y se dedicó a la reorganización de la administración pública y a la reestructuración de la Secretaria de Hacienda.

Los principales hechos de Benito Juárez con el tema hacendario emanados del Gobierno Constitucional fueron:

- El restablecimiento de la Junta de Crédito Público, encargada de administrar las aduanas marítimas, así como de las modificaciones que se hicieron a su organización.

- La medida de cobro de los impuestos en los puntos del consumo y no de la producción.

- El cese de las facultades extraordinarias concedidas a los gobernadores de los estados en el ramo de Hacienda.

- Liberación del cultivo, elaboración y comercio del tabaco y fijación de un impuesto por su consumo.

- Se extinguen los fondos de peajes, minería y judicial.

- Se establece la Lotería Nacional, cuyos productos se destinan a la instrucción pública.

- Se establece la Contribución Federal, que consistió en el $15 \%$ o cuarta parte adicional sobre todo entero realizado en las oficinas fe la Federación y de los estados.

Las oficinas principales de Hacienda tiene por primera vez una dirección específica de contabilidad, se llevan con toda regularidad las cuentas y disposiciones del Ejecutivo y funciona cabalmente la maquinaria administrativa.
Entre las innovaciones fiscales notables de este periodo se encuentra el establecimiento del sistema de contabilidad llamado "partida doble" y la expedición de la Ley del Timbre, la cual fijaba un plazo para la sustitución de papel sellado por las estampillas correspondientes, así como la creación de una oficina especial en la que se imprimieran dichas estampillas y el papel para despachos, títulos y nombramientos. Este es antecedente de la Dirección de impresión de Estampillas y Valores.

\section{Porfiriato}

En año de 1876 Porfirio Díaz es electo presidente por primera vez y no abandona el poder sino hasta el año de 1911. Durante su gobierno, inició un periodo de prosperidad, principalmente con una política de impulso a la construcción de ferrocarriles y el desarrollo de la industria minera, razón por la que se requería la reforma y actualización del sistema fiscal y de la Secretaria Hacienda. Las principales características del sistema fiscal de ese entonces fueron:

- La mayoría de la riqueza del país estaba ligeramente gravada o no pagaba ningún impuesto. Ésta, en gran parte, era controlada por extranjero y algunas familias mexicanas muy adineradas, escapando la porción de su riqueza a la carga impositiva estatal o nacional.

- El consumo se gravaba, sobre todo, en los artículos de primera necesidad.

- El sistema Hacendario federal y estatal tenían establecidos sus propios impuestos y no se tomaban en cuenta entre ellos.

Porfirio Díaz duplicó el Impuesto del timbre, gravo las medicinas cien artículos más, cobró impuestos por adelantado; recaudo 30 millones de pesos, pero gastó más del cuarenta por ciento de esa recaudación, generándose una alta deuda externa pagando demasiados intereses, haciéndose necesario un sistema de tributación controlado y equilibrado. 
Sin embargo, la sociedad mexicana imitaba el lujo y diversiones de las cortes europeas en 1892, en un informe elaborado por el ministro de Hacienda, Matías Romero, se puso de manifiesto la falsa bonanza de la Hacienda Pública de la administración porfirista y los graves problemas económicos de la República, causados por el excesivo gasto en el ambicioso programa ferroviario, la caída de los precios de la planta y los excesivos empréstitos solicitados con réditos relativamente altos.

El Ministro de Hacienda José Yves Limantour en el año de 1893, nivela la Hacienda Pública aumentando las cuotas de los Estados y la Federación reduciendo el presupuesto y las partidas abiertas del Ejecutivo, así como los sueldos de los empleados.

Hacia 1910 por motivo de las fiestas del centenario de la Independencia, Porfirio Díaz inauguró edificios públicos, monumentos y escuelas, se realizaron bailes, banquetes y un gran desfile al que asistieron personalidades de otros lugares del mundo. Panorama que antecedía una revolución.

\section{La revolución}

Tras la caída de la dictadura y el destierro de Porfirio Díaz, se generó desorden en el país situación a la que no escapó la tributación. Los ciudadanos dejaron de pagar impuestos, dado que estaban ocupados en las armas. Cada jefe militar emitía papel moneda y usufructuaban los productos de los derechos de importación y exportación de las aduanas que se encontraban en las regiones ocupadas por cada ejército. Las oficinas recaudadoras de Hacienda eran dejadas a su disposición, a fin de proveerse inmediatamente de fondos, y los ejércitos caudillos que tenían la posesión de regiones petrolíferas recaudaban un impuesto metálico derivado del petróleo.

Los ejércitos revolucionarios contribuyeron a la ruptura del sistema monetario con la emisión de su propio papel moneda, que sin tener ningún apoyo como reserva del Estado, carecía de valor y originaba un rechazo generalizado de la población hacia cualquier forma de billetes llamados "bilimbiques".
Cuando Venustiano Carranza asumió el Poder Ejecutivo de la Nación, se enfrentó ante una grave crisis económica; huelgas, enfrentamientos por el incremento de impuestos, falta de créditos del exterior e inflación causada por las emisiones monetarias de los años anteriores.

Entre 1917 y 1935 se implantan diversos impuestos como servicio por uso de ferrocarriles, impuestos especiales sobre importaciones del petróleo y derivados, impuestos por consumo de luz, impuestos especiales sobre teléfonos, timbres, botellas cerradas, avisos y anuncios. Un cambio importante en el sistema tributario, fu el incremento de los impuestos a los artículos nocivos para la salud $40 \%$ para bebidas alcohólicas, $16 \%$ a la cerveza, y se duplicó el impuesto al tabaco. Simultáneamente se incrementó el impuesto sobre la renta y el de consumo de gasolina. Sin embargo tales medidas generaron beneficios sociales como la implantación del servicio civil, retiro por edad avanzada con pensión y en general se modernizaron los procedimientos administrativos y servicios a la comunidad. "Un hecho que estabilizó la vida política del país fue la promulgación de la Constitución de 1917 que actualmente nos rige."

En el periodo presidencial de Álvaro Obregón, José Vasconcelos fundó la Secretaría de Educación Pública, se crearon nuevas escuelas, se motivó a los maestros para que atendieran las zonas rurales y se promovió la elaboración y distribución de libros para enseñar a leer y escribir.

En los siguientes periodos presidenciales se realizaron diversas obras, se repartieron tierras a los campesinos, se mejoró la situación de los obreros, se aplicaron carreteras y se construyeron canales de riesgos.

No obstante, eran las empresas extranjeras las que administraban los ferrocarriles y explotaban los campos petroleros, y si bien con los impuestos que pagaban se obtuvo dinero para realizar obras públicas, el país seguía con una fuerte dependencia de estas actividades económicas. 


\section{México contemporáneo}

Tuvieron que transcurrir muchos años para que se estabilice la situación y para que los gobiernos hayan modificado las leyes fiscales para disponer de recursos, construir obras y prestar servicios a la colectividad, procurando así una mejor distribución de la riqueza. El sistema tributario de nuestro país en mucho más que un conjunto de disposiciones fiscales, es parte de nuestra historia, de nuestras costumbres y de la idiosincrasia misma de los mexicanos. Así mismo, podemos establecer que en la Constitución Federal de los Estados Unidos Mexicanos de 1857, en el artículo 31, fracción II, estableció la obligación de contribuir con la misma redacción que tiene la Constitución en vigor.

El país requiere que haya más y mejores maestros, escuelas para todos los niños, hospitales, higiene, comida, habitación, caminos, servicios públicos y elementos de bienestar y seguridad común. (ESCOBAR RAMÍREZ, 1999). La implementación de cultura tributaria aplica términos que la mayoría de las veces no se comprenden e interpretan de manera incorrecta, por lo que ocasionan una mala aplicación, por esto es necesario definir elementos que se encuentran ligados con el tema.

\section{Actividad financiera}

El Estado para realizar sus función económica, política y social, debe de allegarse recursos a través de una serio de rubros, a cuyo actuar del Estado, se les denomina "Actividad Financiera del Estado". El fiscalista mexicano Joaquín B. Ortega, la define como "LA actividad que desarrolla el Estado, con el objeto de procurarse los medios necesarios, para los gastos públicos destinados a la satisfacción de las necesidades públicas, y en general, a la realización de sus propios fines"

Para Giannini, dicha actividad no atiende la satisfacción de una necesidad de la colectividad, sino que cumple con una "función instrumental" de suma importancia para el desarrollo de las demás actividades del Estado. La obtención de ingresos puede ser por institutos de derecho privado (Empresas, renta de inmuebles, venta de bienes), así como por institutos de derecho público (Tributos), o por institutos mixtos (empréstitos).
La actividad financiera del Estado tiene su sustento dentro de una de las ramas del Derecho, llamado Derecho Financiero, y es en éste donde encontramos la normatividad referente a la obtención, manejo y erogaciones de recurso

\section{Derecho financiero}

Para conocer donde se encuentra el Derecho Financiero lo ubicaremos dentro del esquema de la clasificación del Derecho. (MOTO SALAZAR, 1994).

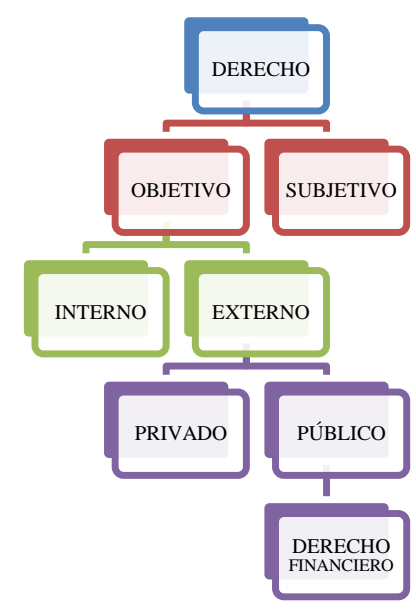

Figura 1 Clasificación del Derecho Fuente: elaboración propia

El derecho financiero forma parte del derecho público, y tiene como sustento el derecho constitucional, dado que el poder legislativo es el encargado de realizar las normas para el desarrollo de la actividad financiera, autorizar anualmente la recaudación de los ingresos y gastos dentro de los límites de la recaudación. El Derecho Financiero es: El conjunto de normas que regulan la obtención, la gestión y el empleo de los medios económicos necesarios para la vida de los entes públicos. (GUIANNINI, 1957) En base a la definición anterior se puede hacer la siguiente división de normas sobre la actividad financiera del Estado:

a) Obtención---Derecho Fiscal.

b) Manejo--Derecho patrimonial.

c) Erogación de recursos-Derecho Presupuestario.

Cada una de estas normas tiene un carácter jurídico propio y diferente sustento. El Derecho Fiscal, constituye una categoría característica del Derecho Tributario. 
El Derecho Patrimonial, está dentro del marco general del Derecho Administrativo. El Derecho Presupuestario, tiene su sustento en el Derecho Constitucional Por lo anterior, podemos deducir que el derecho financiero no tiene autonomía, puesto que depende de la aplicación de diversas ramas del derecho. Dado que en la presenta investigación, lo que nos importa es lo referente a la recaudación de ingresos no enfocaremos a ver lo referente a la captación de recursos. Cuando hablamos de captación de recursos, nos viene a la mente palabras con "Fisco" y "Hacienda", que son de intima relación con la recaudación del Estado.

\section{Derecho fiscal o derecho tributario}

$\mathrm{Al}$ derecho fisca se le puede denominar también Derecho Tributario o Derecho Impositivo.

En México la SCJN nos dice que "FISCO significa, entre otras cosas, la parte de la hacienda pública que se forma con las contribuciones, impuestos y derechos..."

Por lo anterior nos damos cuenta que el Derecho Fiscal es la parte más importante de la actividad financiera del Estado, puesto que se encarga de obtener los ingresos siempre basándose en sus características esenciales y sin olvidar las garantías, individuales.

De la Constitución Política de los Estados Unidos Mexicanos, emana el Derecho tributario Mexicano a través de lo siguiente:

Artículo 31. Son obligaciones de los mexicanos...

Fracción IV. "Contribuir para los gastos públicos, así de la federación, como del D.F. o del Estado y municipio en que residan, de la manera proporcional y equitativa que dispongan las leyes"

El artículo 1ro (sujeto del impuesto y el 6to (momento de causación de las contribuciones y fecha de pago) del CFF, se relacionan para hacer que la ley no deje de lado a los extranjeros puesto que, cuando residan en territorio nacional o con fuente de ingresos en la República tienen la obligación de cubrir el impuesto fijado por las leyes respectivas.

Analizando lo que significa "Tributo", ayudará a entender de mejor manera al Derecho Tributario.
Tributo es "La prestación obligatoria que exige el Estado para atender sus necesidades y realizar así sus fines políticos, económicos y sociales. (RODRÍGUEZ LOBATO, 2002)

Es una presentación obligatoria, comúnmente en dinero, exigida por el Estado en virtud de su poder de imperio y que da lugar a relaciones jurídicas de derecho. (FONROUGUE, 1993)

Siendo que el Estado es el único capaz para cobrar los tributos, debe tener el poder de emitir leyes que establezcan dichos tributos, a éste poder de crear leyes, se le denomina Potestad Tributaria.

\section{Potestad tributaria}

Es la facultad del Estado por virtud del cual puede imponer a los particulares, la obligación de aportar una parte de su riqueza para el ejercicio de las atribuciones que le están encomendadas. (DE LA GARZA, 2006)

La exclusividad del Estado para ejercer la potestad tributaria, es a través del poder legislativo al realizar las leyes, después por el poder ejecutivo al aplicar la ley tributaria y proveer de una esfera administrativa y finalmente, por el poder judicial al dimitir controversias.

\section{Poder tributario de los estados}

El poder tributario de los Estados reside en el artículo 124 de la CPEUM; "Las facultades que no están expresamente concedidas por esta Constitución a los funcionarios federales, se entienden reservadas para los Estados."

Las leyes federales no limitarán la facultad de los Estados para establecer contribuciones que se refieren a ingresos derivados de la prestación de servicios públicos a su cargo y de las contribuciones, sobre la propiedad inmobiliaria, fraccionamiento, división, consolidación, traslación y mejoras así como el cambio de valor.

De lo anterior se derivan distintos términos involucrados con la actividad financiera como ce mencionan a continuación.

ANDRADE-OSEGUERA, Miguel Ángel, PAREDES-BARRÓN, Adriana, BÁRCENAS-PUENTE, José Luis y SILVACONTRERAS, Juan. Antecedentes de la Cultura Tributaria en México. Revista de Aplicaciones del Derecho. 2019 


\section{Contribuciones}

Son los ingresos que percibe el Estado, reconocidas en ley, mediante aportaciones pecuniarias que en forma obligatoria son exigidas a los particulares, y que sirven para que el gobierno del país pueda cumplir con su función pública.

Para entender mejor, qué son las Contribuciones, ya que el CFF no las Define, las podemos explicar como Un concepto genérico que abarca aquello que auxilia a sufragar los gastos del Estado y las podemos dividir en contribuciones forzadas $y$ voluntarias, las primeras son aquellas que la ley fija a cargo de particulares que se adecuen al supuesto previsto por la ley y las segundas son las que derivan de voluntades entre un particular y el Estado, o bien de una declaración unilateral de voluntades entre un particular y el Estado, o bien de una declaración unilateral de voluntad que implica un acto de libertad. (RODRÍGUEZ LOBATO, 2002)

Las contribuciones son denominadas también TRIBUTOS y son ejercidas por el poder que tiene el Estado llamado Poder Tributario.

\section{Los impuestos}

Contribuciones establecidas en Ley que deben pagar las personas físicas y morales que se encuentran en la situación jurídica o de hecho prevista por la misma. (CFF, 2018)

\section{Las aportaciones de seguridad social}

Contribuciones establecidas en ley a cargo de personas que son sustituidas por el Estado en el cumplimiento de obligaciones fijadas por la Ley en materia de seguridad social o a las personas que se beneficien en forma especial por servicios de seguridad social proporcionados por el mismo Estado.

\section{Las contribuciones de mejoras}

Son las establecidas en ley a cargo de personas físicas y morales que se beneficien de manera directa por obras públicas.

\section{Los derechos}

Son contribuciones establecidas en Ley por el uso o aprovechamiento de los bienes del dominio público de la nación, así como por recibir servicios que presta el Estado en sus funciones de derecho público excepto cuando se presten por organismos descentralizados $u$ órganos desconcentrados cuando en este último caso, se trate de contraprestaciones que no se encuentren previstas en la Ley Federal de Derechos.

\section{Los aprovechamientos}

Son los ingresos que percibe el Estado por funciones de derecho público distintos de las contribuciones, se los ingresos derivados de financiamientos y de los que obtengan los organismos descentralizados y las empresas de participación estatal.

\section{Productos}

Son las contraprestaciones por los servicios que preste el Estado en sus funciones de derecho privado, así como por el uso, aprovechamiento o enajenación de bienes del dominio privado. El CFF abarca todo lo referente a la legalización fiscal como: derechos y obligaciones de los contribuyentes, las facultades de las autoridades fiscales, infracciones y delitos fiscales y establece lo referente al procedimiento administrativo para terminar con el juicio contencioso administrativo.

El Código Fiscal de la Federación menciona el término "establecidas por Ley", ya que son varias las que están relacionadas y no se debe dejar de lado a fin de poder cumplir con todas las obligaciones fiscales.

\section{Reglamentos de ley}

Existen otros elementos que auxilian a las leyes como el reglamento, es un acto jurídico formalmente administrativo, tiene su origen en el Presidente de la República y materialmente legislativo porque crea situaciones jurídicas generales abstractas e impersonales, a través de este se desarrollan y complementan las normas de una ley, a fin de hacer más eficaz y expedita su aplicación a los casos concretos, determinando de modo general y abstracto los medios para ello. 
El reglamento tiene por objeto desarrollar y detallar los principios generales contenidos en la ley, para hacer posible y práctica la aplicación de estas. (FRAGA, 1999)

$\mathrm{Su}$ finalidad es tomar el mandato previsto por la Ley y desarrollarlo concretizándolo, cuando sea necesario, para hacerlo efectivo. (SCJN, 2018)

\section{Micelanea fiscal}

Son disposiciones de carácter general necesarias para el ejercicio eficaz, así como para la aplicación de las leyes, tratados y disposiciones que con base en ella expida el SAT que, en su carácter de autoridad podrá emitir.

\section{Decretos}

Órdenes emitidas por la autoridad, que van dirigidas a los gobernados y que sirven para dar una resolución a un caso concreto.

\section{Circular}

Es un documento de orden interno, por el cual se transmiten orientaciones, aclaraciones, información o interpretación legal o reglamentaría del funcionario jerárquicamente superior, a los subordinados, es decir son disposiciones meramente internas, que no atañen al gobernado.

\section{Diferencia entre reglamento y ley}

De acuerdo al diccionario la Ley es una norma jurídica dictada por el legislador, es decir, un precepto establecido por la autoridad competente, en que se manda o prohíbe algo en consonancia con la justicia. Su incumplimiento trae aparejada una sanción, y los Reglamentos son las consecuencias propias que el ordenamiento jurídico concede a la administración, mientras que las disposiciones del poder ejecutivo con fuerza de Ley, por lo que se tiene los siguientes criterios:

a) La ley es superior jerárquicamente al reglamento.

b) Algunas materias, por su trascendencia, solo serán reguladas por la ley y no por el reglamento. c) La ley emana del poder legislativo y el reglamento del ejecutivo.

d) Todo reglamento está vinculado a una ley, no hay reglamento sin ley.

e) Ningún reglamento puede abrogar o derogar a una ley, en tanto que la segunda si puede dejar sin vigencia parcial o total un a un reglamento.

\section{Persona física y persona moral}

Para fines fiscales, es necesario definir si una persona realizará sus actividades económicas como persona física o como persona moral, ya que las leyes establecen un trato diferente para cada una, y de esto depende la forma y requisitos para darse de alta en el Registro Federal de Contribuyentes (RFC) y las obligaciones que adquieran.

Persona física es un individuo con capacidad para contraer obligaciones y ejercer derechos". (SAT, www.sat.gob.mx, 2018). Persona moral es una agrupación de personas que se unen con un fin determinado, por ejemplo, una sociedad mercantil, una asociación civil. (SAT, www.sat.gob.mx, 2018)

\section{Ingresos tributarios}

Son las percepciones que obtiene el Gobierno Federal por las imposiciones fiscales que, en forma unilateral y obligatoria, fija el Estado a las personas físicas y morales. (SAT, www.sat.gob.mx, 2018)

\section{Índice Nacional de Precios al Consumidor (INPC)}

Es un factor que sirve para la actualización a valor presente de bienes, servicios e inversiones. El cálculo de éste corresponde al Banco de México y se publica en el Diario Oficial entre los primeros diez días del mes siguiente. (SAT, www.sat.gob.mx, 2018) 


\section{Resultados}

De acuerdo al artículo 31 de la Constitución Política de los Estados Unidos Mexicanos, los particulares deberán contribuir para los gastos públicos de la Federación, así como de los Estados y Municipios en que se residan, de la manera proporcional y equitativa que dispongan las leyes, a partir de esto, se determinan los efectos que tienen los impuestos para que se cumpla lo anterior, por lo que se puede decir que hay impuestos que se pagan e impuestos que no se pagan, existiendo así infracciones a las normas tributarias, y en estos casos, la autoridad deja de percibir las contribuciones por parte de los contribuyentes por razones que pueden ser consideradas como la evasión y la elusión. El análisis generado da la pauta para conocer la relevancia que a tenido una Cultura Tributaria en la Historia de nuestro país, que desde los tiempos, se ha tenido que contribuir para con el gasto público. La creación de una Cultura Tributaria deberá ser implementada en la educación, a partir del nivel básico, donde se van cimentando los valores y las actitudes de los individuos que en su futuro, serán las generaciones que contribuyan con el estado.

\section{Conclusiones}

Es claro que la percepción que se tiene acerca de las obligaciones, con respecto al paga de contribuciones, hoy en día, es de suma importancia cumplir y tener claro los beneficios que se tiene.

Hoy en día el organismo encargado a la recaudación y uso de los impuestos, sigue en la mejora continua de los procesos y en la implementación de acciones, en las que puedan llegar con un mayor impacto a la sociedad.

El análisis histórico nos permite conocer como desde los antepasados ya manejaban una cultura tributaria de acuerdo a la época, y que con el trascurso del tiempo se fue complementando e impactando en la economía del pueblo.

Hoy en día el estado implementa campañas para cambiar la concepción que se tiene de la obligación de las contribuciones, generando confianza entre los ciudadanos. Siempre tratando de dar solución a los problemas de manera asertiva.
Debemos valorar la riqueza de nuestro país, aprovechar nuestro crecimiento, contribuyendo al desarrollo y fortaleciendo los valores que harán de las futuras generaciones, ciudadanos de éxito.

\section{Referencias}

CFF. (2018). Prontuario Fiscal. México: ECAFSA.

DE LA GARZA, S. F. (2006). Derecho Financiero Mexicano. México: Porrua.

ESCOBAR RAMÍREZ, G. (1999). Prinvipios de Derecho Fiscal. México: OGS Editores.

FONROUGUE, G. (1993). Derecho financiero. México: Depalma.

FRAGA, G. (1999). Derecho Administrativo. México: Porrua.

GUIANNINI. (1957). Instituciones de derecho tributario. Madrid: Derecho financiero.

MOTO SALAZAR, E. (1994). Elementos de derecho. México: Porrua.

PORRAS Y LÓPEZ, A. (1967). Derecho Fiscal. México: Porrua.

RODRÍGUEZ LOBATO, R. (2002). Derecho fiscal. México: Oxford.

SÁNCHEZ LEÓN, G. (1999). Derecho Físcal Mexicano (Decima primer ed., Vol. I). México: Cárdenas Editor y Distribuidor.

SAT. (05 de 05 de 2018). www.sat.gob.mx. Obtenido de www.sat.gob.mx: http://www2.sat.gob.mx/sitio_internet/21_1578 6.html

SAT. (04 de 05 de 2018). www.sat.gob.mx. Obtenido de www.sat.gob.mx: www.sat.gob.mx

SCJN. (04 de 05 de 2018). www.scjn.gob.mx. Obtenido de www.scjn.gob.mx: www.scjn.gob.mx 